\section{Stillbirths before 28 weeks?}

The study on planned home versus planned hospital births ${ }^{1}$ (published Sept. 15) has many strengths, but it has one glaring weakness. It fails to provide the nature and circumstances of the deaths in each group. It is widely recognized that stillbirths prior to 28 weeks are not a reflection of obstetric care. Unless and until the authors are forthcoming about the circumstances of the deaths, we need to reserve judgment about what the study really shows.

Amy B. Tuteur MD

Sharon, Mass., USA

\section{REFERENCE}

1. Janssen PA, Saxell L, Page LA, et al. Outcomes of planned home birth with registered midwife versus planned hospital birth with midwife or physician CMAJ 2009. DOI:10.1503/cmaj.081869

For the full letter, go to: www.cmaj.ca/cgi/eletters /cmaj.081869v1\#174975

DOI:10.1503/cmaj.109-2014

\section{The author responds:}

This is a population-based study ${ }^{1}$ which used data from a provincial perinatal database with no personal identifiers. The charts and therefore the clinical details surrounding each death were not available. In Canada, stillbirth is defined as intrauterine death after 20 weeks gestation. Early neonatal death is from birth to 7 days. Together this time period is referred to as perinatal death and it is a standard mortality rate in Canada. We also examined the time period between 8 to 28 days of life and there were no deaths during this period (late neonatal period) in any of the 3 comparison groups. Following this first broad data search, the 3 groups were matched for comparison. All of the groups had to meet the eligibility requirements for home birth, regardless of planned place of birth. Only those births that occurred between $37+0$ weeks and $<42$ weeks were included in the final analysis.

Lee Saxell MA

BC Women's Hospital, Vancouver, BC

\section{REFERENCE}

1. Janssen PA, Saxell L, Page LA et al. Outcomes of planned home birth with registered midwife versus planned hospital birth with midwife or physician CMAJ 2009. DOI:10.1503/cmaj.081869

For the full letter, go to: www.cmaj.ca/cgi/eletters /cmaj.081869v1\#178829

DOI:10.1503/cmaj.109-2015

\section{Correction}

A Sept. 1 review of the book Death by Prescription: a Father takes on His Daughter's Killer - the Multi-billionDollar Pharmaceutical Industry ${ }^{1}$ said that the UBC Therapeutics Initiative was disbanded. In fact, a task force recommended the academic, drug-review initiative be disbanded but it was not. $C M A J$ regrets the error and apologizes for any inconvenience it may have caused.

\section{REFERENCE}

1. Perry TL. We (do not) stand on guard for thee. CMAJ 2009. DOI:10.1503/cmaj.091353.

DOI:10.1503/cmaj.109-2020

\section{Letters to the editor}

In submitting a letter, you automatically consent to have it appear online and/or in print. All letters accepted for print will be edited by $C M A J$ for space and style. Most references and multiple authors' names and full affiliations will appear online only. (The full version of any letter accepted for print will be posted at cmaj.ca.) 